\title{
Stable and Metastable Cytoskeletal Polymers Carried by Slow Axonal Transport
}

\author{
Ghislaine Filliatreau, ${ }^{1}$ Philippe Denoulet, ${ }^{2}$ Béatrice de Nechaud, ${ }^{2}$ and Luigi Di Giamberardino' \\ 'S.H.F.J., Département de Biologie, CEA, 91406 Orsay, and 'Laboratoire de Biochimie Cellulaire, Collège de France, \\ 75005 Paris, France
}

\begin{abstract}
The proteins carried by the slow axonal transport in the rat sciatic motor axons were radiolabeled by injecting ${ }^{35} \mathrm{~S}-\mathrm{me}$ thionine into the spinal cord, and the distribution of their solubility through the 2 main components of slow transport (SCa and $\mathrm{SCb}$ ) was considered. For this purpose, a cytoskeleton-stabilizing buffer was designed in which a pellet enriched in macromolecular and polymeric structures was separated from the solubilized proteins.

The monomer/polymer ratios for tubulin were quantified in the 2 rate components. Our results indicate that $90 \%$ of the total tubulin was carried with SCa. Of this, $75 \%$ was in a polymeric state, versus only $50 \%$ of the tubulin carried with SCb. The monomeric tubulin recovered in the soluble fraction was concomitantly transported with the polymerized microtubules, suggesting that it might represent metastable regions of these microtubules.
\end{abstract}

The insoluble and soluble fractions of the transported actin were measured. Actin was mostly $(\mathbf{7 0} \%)$ transported with $\mathrm{SCb}$. Of this, more than $80 \%$ was recovered in the soluble fraction, but we cannot say whether it was in a monomeric or polymeric state, nor if it was transported free or bound to a structure solubilized during fractionation. The other $30 \%$ of the actin, most of it transported with $\mathrm{SCa}$, was recovered in the polymer-enriched fraction, probably bound to a stabilized polymer, such as the microtubules.

The neurofilaments, all of which were recovered in the polymer fraction, exhibited a complex transport profile suggesting the existence of 2 populations of motor axons: one with a high neurofilament/microtubule ratio and an average $\mathrm{SCa}$ transport rate of $1.1 \mathrm{~mm} / \mathrm{d}$, and the other with a lower neurofilament/microtubule ratio and an average $\mathrm{SCa}$ transport rate of $2.3 \mathrm{~mm} / \mathrm{d}$.

Our data strongly suggest that the cytoskeletal proteins are in a polymeric state when they move inside the axons with SCa and, possibly, with SCb.

The proteins that constitute the major cytoskeletal polymers of the axon, namely, the microtubules, neurofilaments, and actin microfilaments (Ellisman and Porter, 1980; Hirokawa, 1982;

\footnotetext{
Received Jan. 12, 1987; revised Nov. 12, 1987; accepted Nov. 13, 1987.

The authors wish to thank Mrs. R. Hassig for her invaluable assistance and Mrs. F. Carretero for her technical help. The constructive comments of Dr. R. Lasek are also gratefully acknowledged. Support for this research was provided by grants from INSERM (CRE-85.6008) to P.D., and from the Fondation pour la Recherche Médicale, INSERM (CRE-86.6008), and FIDIA (Abano Terme, Italy) to L.DiG.

Correspondence should be addressed to Luigi Di Giamberardino at the above address.

Copyright (c) 1988 Society for Neuroscience $0270-6474 / 88 / 072227-07 \$ 02.00 / 0$
}

Schnapp and Reese, 1982; Tsukita et al., 1982), move with the slow phase of axonal transport as 2 distinct components, defined according to their protein composition and migration rates: $0.1-$ $2 \mathrm{~mm} / \mathrm{d}$ for slow component a (SCa), and $2-4 \mathrm{~mm} / \mathrm{d}$ for slow component b (SCb) (Hoffman and Lasek, 1975; Mori et al., 1979; Willard et al., 1979; Black and Lasek, 1980).

According to Lasek's structural hypothesis regarding axonal flow (1980) and the sliding polymer model more specifically regarding slow axonal transport (1986), the $a$ and $b$ components each reflect the progression of a distinct set of polymerized structures, able to slide past one another; if true, this would mcan that the SCa component represents a network of interconnected microtubules, neurofilaments, and microfilaments, and the $\mathrm{SCb}$ component a large complex of soluble proteins organized with various degrees of tightness around a carrier structure containing microfilaments (Lasek, 1984, 1986; McQuarrie et al., 1986).

Several pieces of experimental evidence support this elegant theory. First of all, the polymer/monomer ratios measured for tubulin, neurofilament triplet, and actin in the axoplasm of the squid giant axon indicate that 75,95 , and $55 \%$ of each of these proteins, respectively, is either in a polymeric state or bound to an organized structure (Lasek, 1984; Morris and Lasek, 1984).

Second, tubulin, actin, and neurofilament triplet proteins were reported to be present in the detergent-insoluble-fraction proteins carried by slow axonal transport (Tashiro et al., 1984). Third, most of the tubulin transported with SCa appeared to be polymerized in cold-stable microtubules (Brady et al., 1984). And last, photobleaching experiments in PC12 cells have shown that tubulin is in fact transported in the neurites in a coherent and not-free-to-diffuse manner (Keith, 1987).

Nevertheless, none of these investigations have given any indication as to the amounts of tubulin and actin transported with the $\mathrm{a}$ and $\mathrm{b}$ slow components, the kinetics of this transport, or the polymer/monomer ratio of the tubulin and actin transported.

On the other hand, data not supporting Lasek's (1980) hypothesis were also claimed. For example, experiments on the growing axons of isolated cells in tissue culture suggest that tubulin is transported in an unassembled form and that most of the axonal microtubules are stationary (Bambourg et al., 1986). Axonal neurofilaments have also been reported to be partially stationary (Nixon and Logvinenko, 1986).

It is the purpose of this paper to measure the polymer/monomer ratio of the tubulin carried by axonal transport and to establish whether or not the soluble tubulin and the stable microtubules are coherently transported. The possible binding of the actin carried by axonal transport with a stable and meta- 


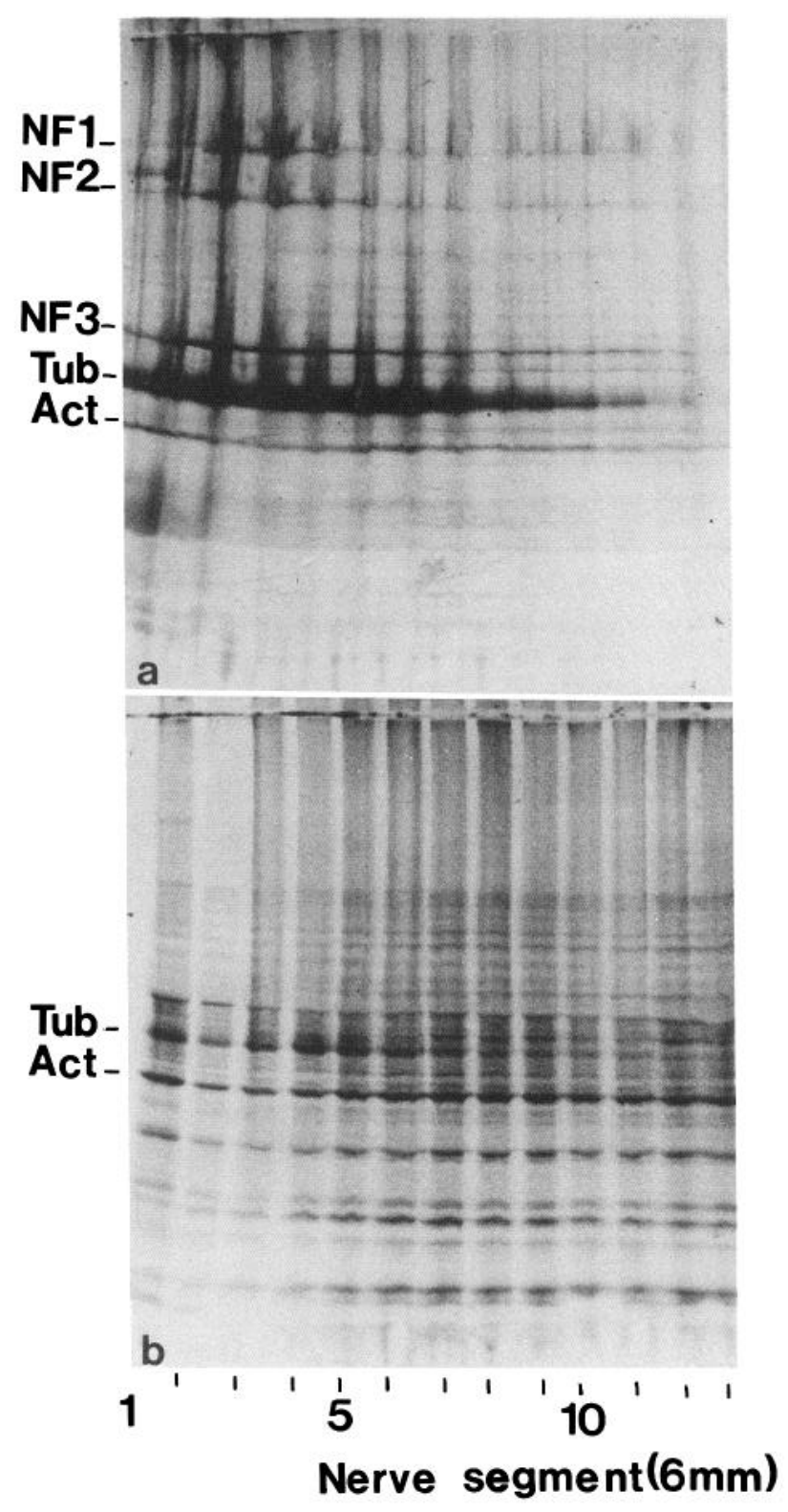

Figure 1. Slowly transported proteins in the pellet $(a)$ and supernatant (b). Radioautographs of the labeled polypeptides present in consecutive $6 \mathrm{~mm}$ segments of the sciatic nerve $21 \mathrm{~d}$ after the radiolabeling pulse. The polypeptides were resolved in $1 \mathrm{D}$ gels. Radioautographic conditions were identical for both the pellet and supernatant from the same nerve; exposure time was adjusted in accordance with the total radioactivity in the nerve in order to obtain a similar degree of darkening from one nerve to another.

stable cytoskeletal structure, as well as the transport of neurofilaments, will also be explored.

\section{Materials and Methods}

Radiolabeling of motor axons. The spinal cord of female Sprague-Dawley rats, 10 weeks old, was exposed by laminectomy at the level of the fourth-fifth lumbar vertebrae, and $120-150 \mu \mathrm{Ci}$ of ${ }^{35} \mathrm{~S}$-methionine (1200 $\mathrm{Ci} / \mathrm{mmol}$; CEA Saclay, France) was injected with a glass capillary (tip width, $20-40 \mu \mathrm{m}$ ) at a point $0.5-1 \mathrm{~mm}$ lateral to the midline to a depth of $1.6-1.8 \mathrm{~mm}$.

Protein fractionation. Rats were decapitated $21 \mathrm{~d}$ after injection and their right sciatic nerve was dissected out, placed on an ice-cold plastic plate, and cut into consecutive $6 \mathrm{~mm}$ segments. Each segment was rapidly homogenized in $150 \mu \mathrm{l}$ of cold cytoskeleton-stabilizing buffer comprising $0.1 \mathrm{M}$ PIPES (piperazine- $N, N^{\prime}$-bis[2-ethanesulfonic acid]), pH 6.9, 5 mM $\mathrm{MgCl}_{2}, 5$ mM EGTA, $0.5 \%$ Triton X-100, 20\% glycerol, $5 \%$ dimethyl sulfoxide, 1 mM PMSF (phenylmethylsulfonyl fluoride), 1 $\mathrm{mg} / \mathrm{ml}$ benzamidine, and $0.16 \mathrm{mg} / \mathrm{ml}$ bacitracin. The homogenates were immediately centrifuged at $80,000 \times g$ for $20 \mathrm{~min}$ at $4^{\circ} \mathrm{C}$ in a Beckman Airfuge. The pellets were resuspended in sample solution and directly submitted to gel electrophoresis, and the supernatants were lyophilized before use.

Polyacrylamide gel electrophoresis. One-dimensional SDS-PAGE was performed according to Laemmli (1970) on slab gel, using a 7.5-15\% linear polyacrylamide gradient. Two-dimensional gels were prepared using a modified version of O'Farrell's procedure (Denoulet et al., 1982).

Radioactivity measurement and normalization. Kodak X-O-Mat X-ray films were exposed to the one-dimensional (1D) gels and analyzed by densitometry using an LKB Ultroscan laser densitometer connected to a Spectra-Physics peak integrator. The optical density of a given protein in a given nerve segment was expressed as the percentage of the sum of the optical densities of that protein in all nerve segments, averaged for the entire group of animals. For mathematical coherence, the same number of nerve segments, always from the second through the thirteenth, was used for all the nerves. The 2D PAGE gels were fluorographed as previously described (Denoulet et al., 1982).

Peptide mapping. In a few cases, an appropriate spot region of a 2D PAGE gel was excised, and the protein concerned was analyzed by limited proteolysis, using Staphylococcus aureus V8 protease (Miles), according to Cleveland et al. (1977).

Immunoblotting. Monoclonal antibodies to the major cytoskeletal proteins were purchased from Amersham (tubulin, tubulin and actin) or Biosys $\left(\mathrm{NF}_{3}\right)$. The proteins in the pellet and supernatant fractions were transferred onto nitrocellulose membrane and submitted to immunological detection using horseradish peroxidase, according to the method of Towbin et al., as described by Cohen et al. (1982).

\section{Results \\ Identification of proteins in the pellet and supernatant fractions}

In more than 80 experiments, the protein compositions of the pellet and supernatant fractions were found to be highly reproducible (see Fig. 2). Some proteins (e.g., neurofilament triplet) were only present in the pellet, but many were entirely solubilized, e.g., albumin, nerve-specific enolase, and creatine phosphokinase. These proteins were identified by peptide mapping after limited proteolysis (data not shown; cf. Eddé et al., 1983). Tubulin and actin were the most abundant of the very few proteins found both in the pellet and supernatant.

\section{Slowly transported proteins}

Nerves were processed $21 \mathrm{~d}$ after the labeling injection, and the distribution of the radioactive proteins along the axons was established by radioautography of the 1D PAGE gels. On the resulting radioautographs, 2 portions of the nerve, segments 2 6 and 9-13 inclusive, exhibited a high level of radioactivity (Fig. 1). Their locations coincided with the 2 radioactive peaks identified as the $\mathrm{SCa}$ and $\mathrm{SCb}$ subcomponents of slow transport. In some experiments, 3 or 4 segments were selected from each portion, pooled, and analyzed by $2 \mathrm{D}$ PAGE as an $\mathrm{SCa}$ or $\mathrm{SCb}$ "window." The protein compositions of the 2 subcomponents were quite different, since the proteins transported in SCa were essentially insoluble and included neurofilament triplet, tubulin, and actin, while those transported in $\mathrm{SCb}$ were mostly soluble and included actin, creatine phosphokinase, nerve-specific enolase, and tubulin. An intermediate filament protein called peripherin, described as a neuronal component of the peripheral nervous system (Portier et al., 1985), was detected in the pellet of the sciatic nerve segments (Fig. 2), and appeared to be transported with $\mathrm{SCa}$, as confirmed by peptide mapping (not shown). 

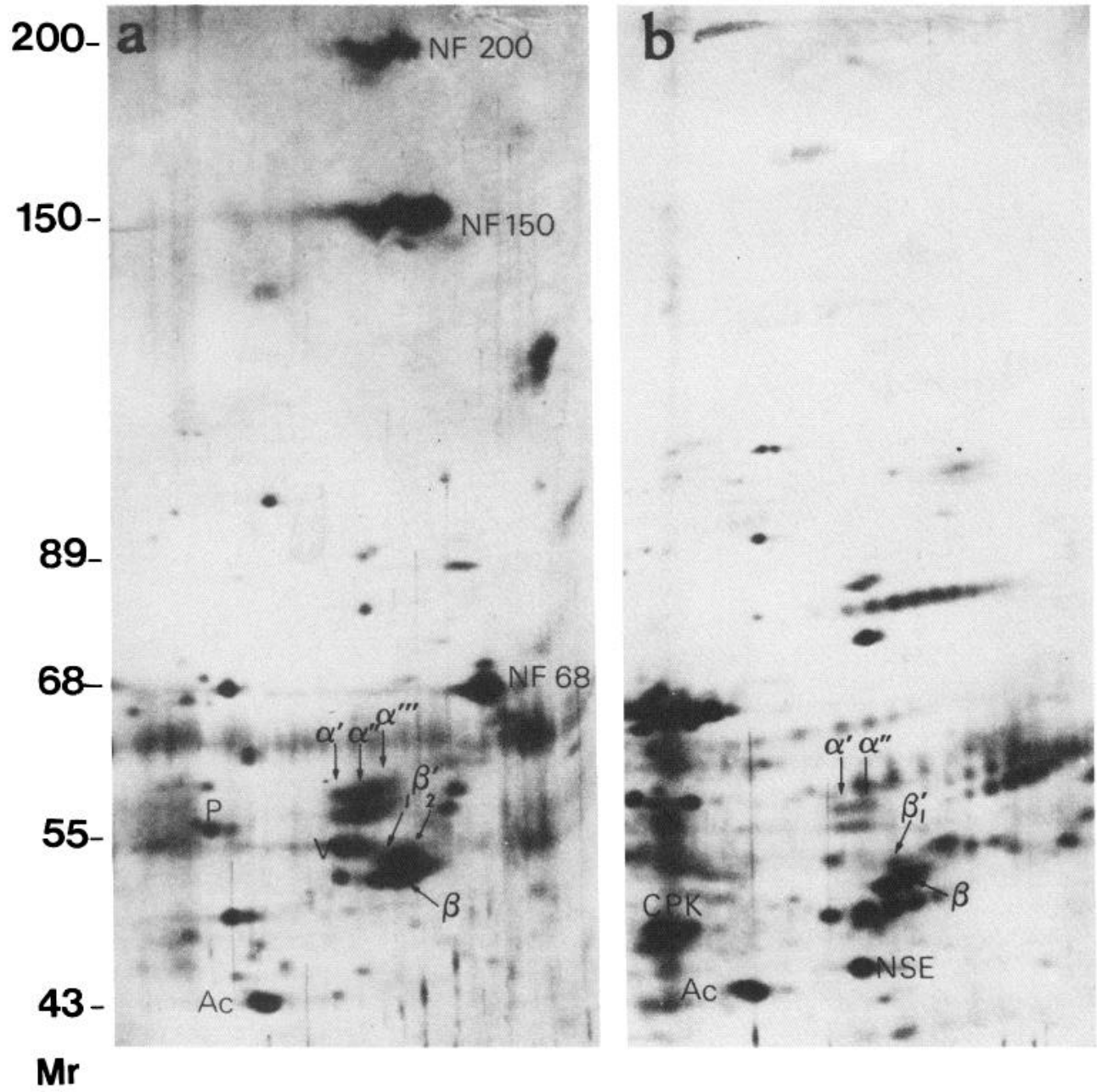

Figure 2. Silver-stained 2D gels of the proteins in the pellet $(a)$ and supernatant $(b)$ from a $6 \mathrm{~mm}$ nerve segment. $P$, peripherin; $A c$, actin; $N F 200, N F 150$, and $N F 68$, neurofilament subunits; $V$, vimentin; $C P K$, creatine phosphokinase; $N S E$, nerve-specific enolase; $\alpha^{\prime}$, $\alpha^{\prime \prime}$, and $\beta, \beta_{i}$, corresponding tubulin isoform.

\section{Individual distributions of radioactive proteins}

The radioactivity of each protein was measured by densitometry of the 1D PAGE radioautographs. Neurofilament triplet was detected in the insoluble fraction only, as shown in Figure 1. Since the 3 subunits of the triplet have been shown to be transported together along the mature axons (Hoffman and Lasek, 1975; Mori et al., 1979; Willard et al., 1979; Nixon and Logvinenko, 1986), we only quantified the distribution of the radioactive $68 \mathrm{kDa}$ neurofilament subunit $\left(\mathrm{NF}_{3}\right)$. More than $75 \%$ of $\mathrm{NF}_{3}$ protein was transported in a sharp, regular peak, at rates ranging from 0.3 to $1.7 \mathrm{~mm} / \mathrm{d}$. Nevertheless, a significant proportion of the fibers moved ahead at rates of up to $2.9 \mathrm{~mm} / \mathrm{d}$, and the fastest radioactivity remained detectable up to the distal segments (Fig. 3). To check this result, an "SCb window" was selected and analyzed by 2D PAGE. The protein spot corresponding to the $\mathrm{NF}_{3}$ coordinates was cut out and subjected to limited proteolysis. The fluorograph of its peptide map was compared with a reference peptide map of spinal $\mathrm{NF}_{3}$. As shown in Figure 4, the result confirmed that this more rapidly transported protein was true $\mathrm{NF}_{3}$. Hence, the 2 radioactive polypeptides detected at 200 and $150 \mathrm{kDa}$, respectively, in the $\mathrm{SCb}$ window can justifiably be considered true neurofilament subunits.

Radioactive tubulin was broadly distributed along the nerve in both the soluble and insoluble fractions (Fig. 1). However, as shown in Figure 3, $68 \%$ of the total radioactivity was insoluble, and most of it was located in the first 9 proximal segments. In this region, almost $75 \%$ of the radioactivity was insoluble, and was transported at rates of $0.2-2.6 \mathrm{~mm} / \mathrm{d}$, whereas only $45 \%$ of the remaining radioactivity, transported at rates greater than $2.6 \mathrm{~mm} / \mathrm{d}$, was insoluble.

Radioactive actin was detected both in the soluble and insoluble fractions. As shown in Figure 3, the soluble radioactivity constituted $75 \%$ of the total, and was transported preferentially at $1.9-3.8 \mathrm{~mm} / \mathrm{d}$, i.e., at rates coinciding with those for $\mathrm{SCb}$. However, a noticeable proportion of the radioactivity was apparently left behind by the main transport peak. In the insoluble fraction, the radioactive actin was fairly regularly distributed over a decreasing proximodistal gradient.

As shown in Figure 1, the radioactive proteins in the soluble fraction were numerous, and most of them were faintly labeled. From the densitograms, we selected 3 of them: S95, S61, and S39, weighing $95 \pm 4,61 \pm 2$, and $39 \pm 1 \mathrm{kDa}$, respectively; they were easily recognizable from one gel to another, and followed their distribution. According to their main transport rates, all of them can be assigned to $\mathrm{SCb}$ (Fig. 3).

\section{Discussion}

The primary aim of this work was to compare the axonal transport of the polymerized and soluble proteins composing the axonal cytoskeleton, and, in particular, to determine the poly- 

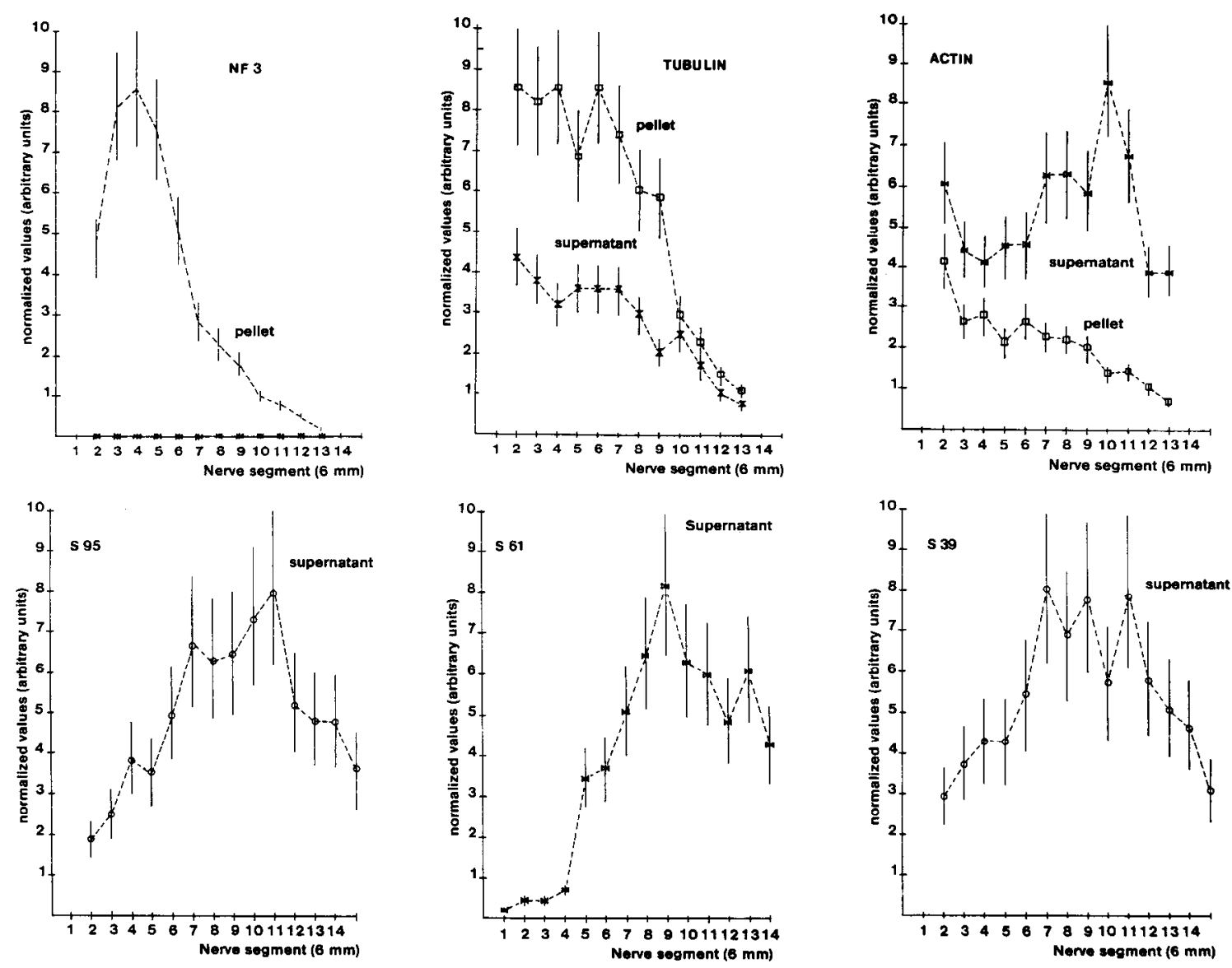

Figure 3. Radioactivity distribution profiles of several slowly transported polypeptides. Cytoskeletal proteins were identified as described in Materials and Methods. S39, S61, and S95 were selected among the entirely soluble proteins and identified by their apparent molecular weights: $95 \pm 4 \mathrm{kDa}$ for $\mathrm{S} 95,61 \pm 2 \mathrm{kDa}$ for $\mathrm{S} 61$, and $39 \pm 2 \mathrm{kDa}$ for $\mathrm{S} 39$.

mer/monomer ratio for tubulin and actin. For this purpose, rat sciatic nerve segments were homogenized in a cytoskeletonstabilizing buffer designed to preserve most of the cytoskeletal polymers in their organized state. Similar buffers have often been used to preserve the whole fibrous system of various lysed cells (Webster et al., 1978; Solomon et al., 1979; Heuser and Kirschner, 1980; Blikstadt and Carlsson, 1982; Tsukita et al., 1982).

As concerns neurofilaments, we can reasonably assume that the neurofilament proteins recovered in the pellet were polymerized, since more than $95 \%$ of the neurofilament protein was shown to be stably polymerized in axons by Morris and Lasek (1982).

In the same study, Morris and Lasek showed that a significant fraction of the insoluble tubulin represents stably polymerized microtubules (Morris and Lasek, 1982, 1984). Microtubules that resist depolymerization by cold and antimitotic drugs were also observed in several types of axons (see, for example, Morris and Lasek, 1982; Heidemann et al., 1984; Donoso, 1986). These insoluble microtubules are thought to represent stable regions along the axonal microtubules (Sahenk and Brady, 1987). Hence, it is justified to suppose that the pellet obtained with our buffer, which is similar to buffers used to stabilize microtubules in tissue culture and homogenate (Pipeleers et al., 1977; Rodriguez and Borisy, 1979; Solomon et al., 1979; Olmsted, 1981; Black et al., 1984), contains the axonal microtubules preserved in their polymerized state.
Symmetrically, one can question whether some polymerization of microtubules could have occurred during the fractionation procedure, since our stabilizing buffer resembled, in several respects, the buffers designed to promote the in vitro polymerization of microtubules. This is unlikely, however, since all the experimental steps were completed at $4^{\circ} \mathrm{C}$ without the addition of nucleotides, 2 conditions that do not favor polymerization (Dustin, 1978). To ensure that there was no polymerization, we also performed a test experiment in which we used the radioactive supernatant of an injected nerve segment to homogenize an unlabeled nerve segment. When the homogenate was centrifuged, the radioactivity remaining in the pelleted polymers was less than $4 \%$ of that recovered from the initial labeled segment; this experiment not only indicated that no polymerization of tubulin occurred during fractionation, but also provided evidence that the unpolymerized tubulin did not contaminate the pellet. Hence, it can be assumed that the ratio of the radioactivity of the tubulin found in the pellet to that found in the supernatant constitutes a reliable index of the polymer/monomer ratio for the transported tubulin, as discussed by Morris and Lasek (1984).

The stabilizing effect of this type of buffer has also been shown to be effective for actin filament bundles in Hela cell cultures (Bravo et al., 1982). Nevertheless, we cannot entirely exclude the possibility that some microfilaments were depolymerized during the homogenization procedure, as was observed by physical measurements in squid giant axon (Morris and Lasek, 1984). 
In addition, on account of the short centrifugation step used here to separate the pellet from the supernatant, short microfilaments should have remained in the supernatant. Hence, the radioactive actin molecules or microfilaments that stayed in the pellet probably did so because they were bound to an insoluble polymer, such as microtubules or neurofilaments (Metuzals and Mushynski, 1974; Sattilaro and Dentler, 1982; Pollard et al., 1984; Papasozomenos and Payne, 1986). Therefore, the pellet/ supernatant ratio of the radioactivity bound to actin probably does not reflect the polymer/monomer ratio of this protein, but rather gives an estimate of the ratio of actin binding to other cytoskeletal polymers, which is also very useful (Lasek, 1986).

Regarding the proteins exclusively recovered in the supernatant fraction, such as $\mathbf{S 9 5}$, S61, and S39, again we cannot say whether they were depolymerized during the homogenization procedure. It can be said, however, that they were not stable polymers, nor were they bound to a stably polymerized structure.

\section{Monomer/polymer ratio of transported tubulin}

The distribution of radioactive tubulin did not exhibit a clearcut peak for either its soluble or insoluble fraction. Nevertheless, 2 main regions could be clearly distinguished: the first extended up to the ninth segment, and was characterized by a polymer/ monomer ratio of more than 2; in the second region, beyond the ninth segment, this ratio dropped very sharply to around 1 .

The first region corresponds to a transport rate of 0.6-2.6 $\mathrm{mm} / \mathrm{d}$ and included more than $90 \%$ of the total radioactive tubulin present in the nerve. The high polymer/monomer ratio, very similar to that measured in squid axon (Morris and Lasek, 1984), indicates that a large fraction of the tubulin transported with SCa was polymerized. Moreover, this ratio was constant, which suggests coherent transport of the polymerized and soluble tubulin.

Some of the microtubules found in this region might interact with the neurofilaments, certain microfilaments, and their crossbridging proteins, thus constituting the network described in morphological observations (Hirokawa, 1982; Schnapp and Reese, 1982; Tsukita et al., 1982).

The second region of tubulin distribution found here corresponds to transport rates of more than $2.9 \mathrm{~mm} / \mathrm{d}$, typical of $\mathrm{SCb}$. Here, again, the polymer/monomer ratio was constant throughout the region, and seems to reflect the coherent conveyance of microtubules and an equal quantity of soluble monomers with which they might exchange during their journey along the axon.

In accordance with these results, studies comparing tubulin moving with $\mathrm{SCa}$ to tubulin moving with $\mathrm{SCb}$ showed that a smaller proportion of tubulin moving at $\mathrm{SCb}$ rates is insoluble in the optic (Brady and Black, 1986) and sciatic (Tashiro et al., 1984) nerves.

\section{Transport profile of the $\mathrm{NF}_{3}$ neurofilament subunit}

The present analysis of the distribution of neurofilament proteins was limited to the $70 \mathrm{kDa}$ subunit, called here $\mathrm{NF}_{3}$. This protein exhibited a radioactive distribution (Fig. 3) with a sharp peak in the 4th segment and a shoulder located at the 8th segment, which respectively correspond to average transport rates of 1.1 and $2.3 \mathrm{~mm} / \mathrm{d}$. Hence, the sharp major peak corresponds to the rates for the SCa component, while the minor faster peak corresponds to the slowest rates for the $\mathrm{SCb}$ component. This faster peak has been described by others in the rat optic and

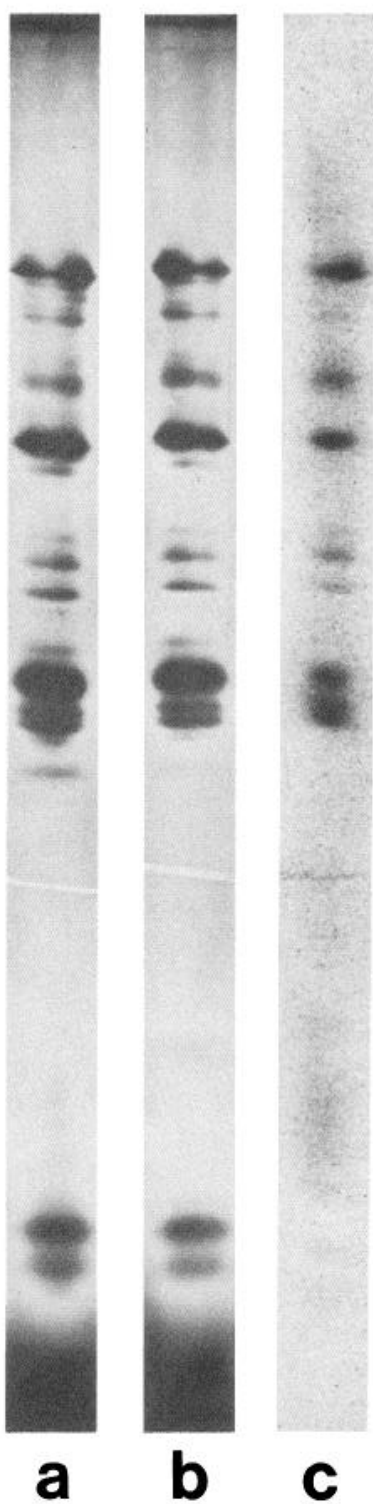

Figure 4. Silver-stained peptide maps of spinal and nerve $\mathrm{NF}_{3}$. The $\mathrm{NF}_{3}$ protein spots were cut out from a $2 \mathrm{D}$ gel stained with Coomassie blue and digested with V8 protease ( $5 \mathrm{ng} /$ well). Lane $a$, spinal $\mathrm{NF}_{3}$; lane $b$, nerve $\mathrm{NF}_{3}$ present in the pellet from an $\mathrm{SCb}$-containing region of a nerve processed $21 \mathrm{~d}$ after pulse radiolabeling; lane $c$, fluorograph of lane $b$.

sciatic nerves (McQuarrie et al., 1986). Its presence is somewhat puzzling, since it seems to indicate that also $\mathrm{SCb}$, though in a minor proportion, contain neurofilaments. An alternative explanation could be the existence of 2 distinct classes of motor axons in the rat sciatic nerve, in which the neurofilament transport rates are 1.1 and $2.3 \mathrm{~mm} / \mathrm{d}$, respectively. Differences in the rates and protein compositions of $\mathrm{SCa}$ and $\mathrm{SCb}$ among different axons have indeed been reported in a comparative study of optic and sciatic nerves (McQuarrie et al., 1986), in the motor and parasympathetic axons of the oculomotor nerve (Paggi et al., 1986), in central and peripheral branches of the dorsal root ganglion cells (Mori et al., 1979), and in developing nerves (Hoffman et al., 1983, 1985). If true, this explanation would also explain why we did not observe 2 clearly separated peaks for the tubulin carried with the $\mathrm{SCa}$ and $\mathrm{SCb}$ components, respectively, since the SCa peak of the faster axons would then 
have fallen between the $\mathrm{SCa}$ and $\mathrm{SCb}$ peaks of the slower axons. Also, the axons with the faster SCa rate seem to display a smaller neurofilament/microtubule ratio, which would suggest that their caliber is smaller (Hoffman et al., 1985).

\section{Transport profiles of solubilized and insoluble actin}

The difference between the profiles of the radioactive actin found in the pellet and supernatant, respectively, indicates that this protein is carried inside the axon in 2 different ways. The actin found in the pellet might be present in one of 3 forms: as bundles of filaments (Bravo et al., 1982), or as short microfilaments or single molecules bound to one of the polymers found in the pellet. In the latter case, the stable microtubules carried with both $\mathrm{SCa}$ and $\mathrm{SCb}$ would be the most likely binding polymers, owing to the similarity of their profile to that of actin (Fig. 3). As regards the radioactive actin found in the supernatant, it might be carried either in soluble form, as monomers or short polymers, as suggested above, or have bound to a metastable structure that was not preserved during our fractionation procedure. It should, however, be noted that most of the radioactive actin found in the supernatant was transported with $\mathrm{SCb}$ at an average rate of $2.9 \mathrm{~mm} / \mathrm{d}$. Here again, the presence of 2 classes of motor axons would explain the blurred profiles.

\section{Transport profiles of proteins found only in the supernatant fraction}

Most of the proteins carried with the SCb component were found only in the supernatant fraction. The 3 we selected as representative of this class, i.e., S95, S61, and S39, respectively exhibited radioactivity peaks at the 9 th segment, between the 7 th and 11 th segments, and at the 11 th segment (Fig. 3). These peaks corresponded to average transport rates of 2.6, 2-3.1, and 3.1 $\mathrm{mm} / \mathrm{d}$, respectively. Further, S61 left no trail, since its radioactivity was almost undetectable up to the 6 th segment, whereas S39 and S95 already left substantial trails at segment 2 . All these proteins exhibited a shoulder between the 12th and 13th segments, probably reflecting the cxistence of 2 classcs of axons, as already suggested.

Judging from their transport rates, all these proteins are carried with the $\mathrm{SCb}$ component. Their radioactive distributions along the nerve might reflect their differential interactions with the $\mathrm{SCa}$ and $\mathrm{SCb}$ carrier structures. For instance, proteins $\mathrm{S} 95$ and $\mathrm{S} 39$ seemed to interact with both $\mathrm{SCa}$ and $\mathrm{SCb}$, and their profiles were in fact very similar to the one found for the soluble actin. Protein S61, on the contrary, seemed to be exclusively transported with $\mathrm{SCb}$.

\section{Conclusions}

In spite of the simple separation method used to carry out this study, reliable results were obtained for the polymer/monomer ratio of the transported tubulin, and of the transported actin or microfilaments tightly bound to a cytoskeletal carrier polymer, probably consisting of microtubules (Papasozomenos and Payne, 1986). Our observations confirm the existence of at least 2 classes of axonal microtubules (Black et al., 1984; Brady et al., 1984; Tashiro et al., 1984; Brady and Black, 1986), respectively carried with $\mathrm{SCa}$ and $\mathrm{SCb}$. They indicate that $75 \%$ of the tubulin carried with $\mathrm{SCa}$ and $50 \%$ of that carried with $\mathrm{SCb}$ are in a stable polymeric state, while the rest, recovered here in the supernatant, is concomitantly carried with the stable polymers and could be in a monomer-polymer equilibrium. The presence of this tubulin does not necessarily reflect the existence of a third class of microtubules, but might indicate the presence of metastable regions of various sizes, located at the end of or between stable microtubular regions. Hence, the microtubules carried with SCa and $\mathrm{SCb}$ could only differ in the size of their metastable regions. These 2 populations of microtubules might well correspond to those described by Tashiro and coworkers (1984).

It would be arbitrary to directly compare the cold-stability of the microtubules we recovered in the pellet with that reported by Brady and coworkers for the microtubules transported with $\mathrm{SCa}$ in the retinal ganglion cell axons of guinea pigs (Brady et al., 1984) because of the different homogenization media used in the 2 separation procedures. For the same reason, no sound comparisons can be made between our tubulin and the cytoplasmic- and particulate-bound transported tubulin described by Goodrom and Morell (1982). It seems reasonable to suggest that the cold-labile microtubules correspond to the metastable region described here, and the cold-stable microtubules to the stable microtubule regions. These stable regions might also correspond to the nucleating elements required for microtubule assembly, as proposed by Heidemann and coworkers (Heidemann et al., 1984; Baas and Heidemann, 1986; Joshi et al., 1986). If the present $\mathrm{SCb}$ and $\mathrm{SCa}$ components are comparable to the 2 classes of microtubules recently described in lobster axons (Miller et al., 1987), the microtubules carried with the $\mathrm{SCb}$ components seem the most likely substrates for vesicle transport, and those carried with the SCa components would probably be the architectural microtubules.

The distribution of the transported actin suggests that some microfilaments or actin molecules are bound to the stable microtubules that are mostly carried with SCa. At the same time, most of the actin molecules or short microfilaments are carried with $\mathrm{SCb}$, either in a free state or woven into a metastable carrier web (Lasek et al., 1984; Lasek, 1986) that might have been dissociated during our fractionation procedure.

Finally, the 2 rate components of transported neurofilaments observed here are consistent with the existence of 2 classes of motor fibers, one with a high neurofilament/microtubule ratio and an average $\mathrm{SCa}$ transport rate of $1.1 \mathrm{~mm} / \mathrm{d}$, and the other with a low neurofilament/microtubule ratio and an average $\mathrm{SCa}$ transport rate of $2.3 \mathrm{~mm} / \mathrm{d}$.

In conclusion, the present quantitative analysis of the polymeric state of the cytoskeletal proteins carried inside the motor axons of rat sciatic nerves supports the hypothesis suggested by Lasek (1986) that the polymers are the natural units of slow axonal transport.

\section{References}

Baas, P. W., and S. R. Heidemann (1986) Microtubule reassembly from nucleating fragments during the regrowth of amputated neurites. J. Cell Biol. 103: 917-927.

Bambourg, J. R., D. Bray, and K. Chapman (1986) Assembly of microtubules at the tip of growing axons. Nature 231: 788-790.

Black, M. M., and R. J. Lasek (1980) Slow components of axonal transport: Two cytoskeletal networks. J. Cell Biol. 86: 616-623.

Black, M. M., M. Cochran, and J. T. Kurdyla (1984) Solubility properties of neuronal tubulin: Evidence for labile and stable microtubules. Brain Res. 295: 255-263.

Blikstadt, I., and L. Carlsson (1982) On the dynamics of the microfilament system in Hela cells. J. Cell Biol. 93: 122-128.

Brady, S. T., and M. M. Black (1986) Axonal transport of microtubule proteins: Cytotypic variation of tubulin and MAPS in neurons. Ann. NY Acad. Sci. 466: 199-217.

Brady, S. T., M. Tytell, and R. J. Lasek (1984) Axonal tubulin and axonal microtubules: Biochemical evidence for cold stability. J. Cell Biol. 99: 1716-1724. 
Bravo, R., S. V. Small, S. J. Fey, P. M. Larsen, and J. E. Celis (1982) Architecture and polypeptide composition of Hela cytoskeletons. J. Mol. Biol. 154: 121-143.

Bray, D., and C. Thomas (1976) Unpolymerized actin in fibroblast and brain. J. Mol. Biol. 105: 527-544.

Cleveland, D. W., S. G. Fischer, M. W. Kirschner, and U. K. Laemmli (1977) Peptide mapping by limited proteolysis in sodium dodecyl sulfate and analysis by gel electrophoresis. J. Biol. Chem. 252: 11021106.

Cohen, J., A. Adoutte, S. Grandchamp, L. M. Houdebine, and J. Beisson (1982) Immunocytochemical study of microtubular structures throughout the cell cycle of paramecium. Biol. Cell. 44: 35-44.

Denoulet, P., B. Edde, C. Jeantet, and F. Gros (1982) Evolution of tubulin heterogeneity during mouse brain development. Biochimie 64: $165-172$.

Donoso, J. A. (1986) Microtubule stability along mammalian peripheral nerves. J. Neurobiol. 17: 383-403.

Dustin, P. (1978) Microtubules, Springer-Verlag, New York, pp. 4654.

Eddé, B., H. Jakob, and M. Darmon (1983) Two specific markers for neural differentiation of embryonal carcinoma cells. EMBO J. 2: 14731478.

Ellisman, M. H., and K. R. Porter (1980) Microtrabecular structure of the axoplasmic matrix: Visualization of cross-linking structures and their distribution. J. Cell Biol. 87: 464-479.

Goodrom, J., and P. Morell (1982) Comparison of axonal transport of cytoplasmic- and particulate-associated tubulin in rat optic system. J. Neurochem. 39: 443-451.

Heidemann, S. R., M. A. Hamborg, S. J. Thomas, B. Song, S. Lindley, and D. Chu (1984) Spatial organization of axonal microtubules. J. Cell Biol. 99: 1289-1295.

Heuser, J. E., and M. W. Kirschner (1980) Filament organization revealed in platinum replicas of freeze dried cytoskeletons. J. Cell Biol. 86:212-234.

Hirokawa, N. (1982) Cross-linker system between neurofilaments, microtubules and membranous organelles in frog axons revealed by the quick-freeze, deep-etching method. J. Cell Biol. 94: 129-142.

Hoffman, P. N., and R. J. Lasek (1975) The slow component of axonal transport. Identification of major structural polypeptides of the axon and their generality among mammalian neurons. J. Cell Biol. 66: $351-366$.

Hoffman, P. N., R. J. Lasek, J. W. Griffin, and D. L. Price (1983) Slowing of the axonal transport of neurofilament proteins during development. J. Neurosci. 3: 1694-1700.

Hoffman, P. N., J. W. Griffin, B. G. Gold, and D. I. Price (1985) Slowing of neurofilament transport and the radial growth of developing nerve fibers. J. Neurosci. 5: 2920-2929.

Joshi, H. C., P. Baas, D. T. Chu, and S. R. Heidemann (1986) The cytoskeleton of neurites after microtubule depolymerization. Exp. Cell Res. 163: 233-245.

Keith, C. M. (1987) Slow transport of tubulin in the neurites of differentiated PC1 2 cells. Science 235: 337-339.

Laemmli, U. K. (1970) Cleavage of structural protein during the assembly of the head of the bacteriophage 14. Nature 227: 680-685.

Lasek, R. J. (1980) Axonal transport: A dynamic view of neuronal structures. Trends Neurosci. 3: 87-91.

Lasek, R. J. (1984) The structure of axoplasm. Curr. Top. Membr. Transport 12: 39-53.

I asek, R. J. (1986) Polymer sliding in axons. J. Cell Sci. (Suppl. 5): 161-179.

Lasek, R. J., J. A. Garner, and S. T. Brady (1984) Axonal transport of the cytoplasmic matrix. J. Cell Biol. 99: 212S-221S.

McQuarrie, I. G., S. T. Brady, and R. J. Lasek (1986) Diversity in the axonal transport of structural proteins: Major differences between optic and spinal axons in the rat. J. Neurosci. 6: 1593-1605.

Metuzals, J., and W. E. Mushynski (1974) Flectron microscope and experimental investigations of the neurofilamentous network in Deiter's neurons. J. Cell Biol. 61: 701-722.

Miller, R. H., R. J. Lasek, and M. J. Katz (1987) Preferred microtubules for vesicle transport in lobster axons. Science 235: 220-222.

Mori, H., Y. Komiya, and M. Kurokawa (1979) Slowly migrating axonal polypeptides. J. Cell Biol. 82: 174-184.

Morris, J. R., and R. J. Lasek (1982) Stable polymers of the axonal cytoskeleton: The axoplasmic ghost. J. Cell Biol. 92: 192-198.

Morris, J. R., and R. J. Lasek (1984) Monomer-polymer equilibria in the axon: Direct measurement of tubulin and actin as polymer and monomer in axoplasm. J. Cell Biol. 98: 2064-2076.

Nixon, R. A., and B. K. Logvinenko (1986) Multiple fates of newly synthesized neurofilament proteins: Evidence for a stationary neurofilament network distributed nonuniformly along axons of the retinal ganglion cell neurons. J. Cell Biol. 102: 647-659.

Olmsted, J. B. (1981) Tubulin pools in differentiating neuroblastome cells. J. Cell Biol. 89: 418-423.

Paggi, P., R. L. Price, and R. J. Lasek (1986) The transport rate and organization of neurofilaments differ in somatic motor and parasympathetic oculomotor axons. Soc. Neurosci. Abstr. 12: 1571.

Papasozomenos, S. C., and M. R. Payne (1986) Actin immunoreactivity localizes with segregated microtubules and membranous organelles in the subaxolemmal region in the $\beta \beta^{\prime}$ iminodipropionitrile axon. J. Neurosci. 6: 3483-3491.

Pipeleers, D. G., M. A. Pipeleers-Marechal, P. Sherline, and D. M. Kipnis (1977) A sensitive method for measuring polymerized and depolymerized forms of tubulin in tissues. J. Cell Biol. 74: 341-350.

Pollard, T. D., S. C. Selden, and P. Maupin (1984) Interaction of actin filaments with microtubules. J. Cell Biol. 99: 33S-37S

Portier, M. M., B. de Nechaud, and F. Gros (1985) Peripherin, a new member of the intermediate filament protein family. Dev. Neurosci. 6: 335-344.

Rodriguez, J. A., and G. G. Borisy (1979) Tyrosination state of free tubulin subunits and tubulin disassembled from microtubules of rat brain tissue. Biochem. Biophys. Res. Commun. 89: 893-899.

Sahenk, Z., and S. T. Brady (1987) Axonal tubulin and microtubules: Morphologic evidence for stable regions on axonal microtubules. Cell Motil. and Cytoskel. 8:155-164.

Sattilaro, R. F., and W. L. Dentler (1982) The association of MAP2 with microtubules, actin filaments and coated vesicles. In Biological Functions of Microtubules and Related Structures, M. Sakai, H. Mohri, and G. G. Borisy, eds., pp. 297-309, Academic, Tokyo.

Schnapp, B. J., and T. S. Reese (1982) Cytoplasmic structures in rapid frozen axons. J. Cell Biol. 94: 667-679.

Solomon, F., M. Magendantz, and A. Salzman (1979) Identification with cellular microtubules of one of the coassembling microtubuleassociated proteins. Cell 18: 431-438.

Tashiro, T., M. Kurokawa, and Y. Komya (1984) Two populations of axonally transported tubulin, differentiated by their interaction with neurofilaments. J. Neurochem. 43: 1220-1225.

Tsukita, S., J. Usukura, S. Tsukita, and H. Ishikawa (1982) The cytoskeleton in myelinated axons: A freeze-etch replica study. Neuroscience 7: 2135-2147.

Webster, R. F., D. Henderson, M. Osborn, and K. Weber (1978) Three dimensional electron microscopical visualization of the cytoskeleton of animal cells: Immunoferritin identification of actin and tubulin containing structures. Proc. Natl. Acad. Sci. USA 75: 5511-5515.

Willard, M., M. Wiseman, J. Levine, and P. Skene (1979) Axonal transport of actin in rabbit retinal ganglion cells. J. Cell Biol. 81: 581 585. 